\title{
Analisis Gaya Kepemimpinan dalam Upaya Meningkatkan Kinerja Karyawan Bagian Sales Modern Trade PT. Pinus Merah Abadi Cabang Sidoarjo
}

\author{
*Dewi Alviana, Haryono, Enny Istanti \\ Program Studi Manajemen Fakultas Ekonomi dan Bisnis \\ Universitas Bhayangkara Surabaya, Indonesia
}

DOI: $10.46821 /$ benchmark.v2i1.222

\begin{abstract}
Abstrak
Penelitian ini bertujuan untuk mengetahui gaya kepemimpinan yang diterapkan pemimpin dalam upaya meningkatkan kinerja karyawan bagian sales modern trade PT. Pinus Merah Abadi cabang Sidoarjo. Data yang digunakan adalah data primer dan sekunder. Metode analisis yang digunakan ialah analisis deskriptif dan uji kebasahan menggunakan triangulasi. Sampel dalam penelitian ini seluruh karyawan bagian sales modern trade (MT) sebanyak 20 orang. Hasil dari penelitian ini adalah Gaya kepemimpinan yang diterapkan oleh pemimpin PT. Pinus Merah Abadi cabang Sidoarjo menggunakan gaya kepemimpinan transformasional dan demokratis. Gaya kepemimpinan transformasional tersebut terlihat dari bagaimana cara pemimpin memiliki rencana perubahan besar dan terarah terhadap visi, misi dan strategi perusahaan. Namun pemimpin juga menggunakan gaya kepemimpinan demokratis. Gaya kepemimpinan tersebut terlihat dari pemimpin mengutamakan musyawarah dan mengambil keputusan sesuai dengan tujuan perusahaan. Kinerja karyawan yang ada saat ini telah memenuhi kriteria dalam penilaian kinerja, namun ada beberapa kendala dalam upaya meningkatkan kinerja karyawan seperti ada beberapa karyawan yang masih belum dapat menyelesaikan tugas-tugasnya.
\end{abstract}

Kata Kunci: Gaya Kepemimpinan, Kinerja Karyawan.

\begin{abstract}
This study aims to determine the leadership style applied by the leader in an effort to improve the performance of employees of the modern trade sales section of PT. Pinus Merah Abadi Sidoarjo branch. The data used are primary and secondary data. The analytical method used is descriptive analysis and wetness test using triangulation. The sample in this study were all employees of the modern trade (MT) sales department as many as 20 people. The result of this research is the leadership style applied by the leader of PT. Pinus Merah Abadi Sidoarjo branch uses a transformational and democratic leadership style. The transformational leadership style can be seen from how the leader has a major and directed change plan towards the company's vision, mission and strategy. But the leader also uses a democratic leadership style. This leadership style can be seen from the leader prioritizing deliberation and making decisions in accordance with company goals. The current performance of employees has met the criteria in the performance appraisal, but there are several obstacles in improving employee performance such as some employees who are still unable to complete their tasks.
\end{abstract}

Keywords: Leadership Style, Employee Performance.

*Corresponding Author:

Hal: 60-69

Email: alvianadewi1997@gmail.com 


\section{PENDAHULUAN}

Manajemen sumber daya manusia merupakan faktor yang berperan sangat penting dalam perusahaan. tanpa adanya manajemen sumber daya manusia yang tidak berkualitas dan tidak dikelola dengan baik maka perusahaan akan sulit berjalan dan tidak beroperasi dengan semestinya meskipun kebutuhan sumber daya yang lain sudah terpenuhi.Sumber daya manusia merupakan modal dasar pembangunan nasional, oleh karena itu, makakualitas sumber daya manusia senantiasa sangat berperan besar dalam kesuksesan organisasi. Enny (2020), salah satu faktor sumber daya manusia dalam perusahaan adalah seorang karyawan yang bertugas sebagai penunjang keberhasilan perusahaan dalam bekerja, berperilaku, dan menjalankan peran atau tugasnya untuk mencapai tujuan dan target yang telah ditetapkan oleh perusahaan agar mendapatkan hasil yang optimal. Selain karyawan peran seorang pemimpin juga berpengaruh dalam keberhasilan perusahaan. Menurut (Hasibuan 2016:13), mengatakan bahwa, pemimpin adalah seseorang yang mempergunakan wewenang kepemimpinannya untuk mengarahkan orang lain serta bertanggung jawab atas pekerjaan orang tersebut dalam mencapai suatu tujuan.

Pemimpin pada dasarnya memang memiliki perilaku yang berbeda dalam memimpin organisasi, perilaku pemimpin ini disebut dengan gaya kepemimpinan. Menurut Wahyudi (2017), gaya kepemimpinan merupakan cara perilaku yang khas dari seorang pemimpin terhadap para anggota kelompoknya. Sehingga gaya kepemimpinan itu sendiri merupakan suatu cara yang diterapkan oleh pimpinan pada situasi tertentu yang bertujuan untuk mempengaruhi karyawannya agar mau melakukan apa yang diperintahkan oleh pimpinan sehingga dapat mencapai tujuan perusahaan.

PT. Pinus Merah Abadi merupakan salah satu perusahaan bergerak dalam bidang distributor penjualan makanan ringan. Objektivitas perusahaan ini adalah penjualan, sehingga karyawan terbanyak berada dibagian sales. Dalam mencapai tujuan perusahaan diperlukan profesionalitas dan produktivitas kerja yang tinggi sehingga mampu menyediakan kebutuhan pasar. Namun untuk mencapai tujuan perusahaan, PT. Pinus Merah Abadi memiliki kendala yaitu terbatasnya sumber daya manusia.

Pada tahun 2019 PT. Pinus Merah Abadi pernah mengalami pengurangan karyawan dan penyempitan devisi area. Hal tersebut juga berdampak dibagian sales modern trade (MT), sebelum adanya pengurangan karyawan sales merchandiser (SMD) berjumlah 32 orang dan saat ini hanya tersisa 16 orang sehingga menyebabkan beban kerja yang diberikan tentunya semakin banyak. Dari fenomena yang terjadi sering kali adanya penurunan kinerja karyawan seperti tidak capai target dan kurangnya komunikasi antara atasan dan bawahan. Hal tersebut tentunya membuat pemimpin PT. Pinus Merah Abadi terus berupaya dalam meningkatkan kinerja karyawan yang ada dengan cara menerapkan gaya kepemimpinan yang tepat dan menyesuaikan situasi dan kondisi yang ada pada perusahaan. Dengan adanya penerepan gaya kepemimpinan yang tepat tentunya dapat menghasilkan keuntungan bagi perusahaan kedepannya sehingga kerja sama antar perusahaan lainnya bisa berjalan dengan baik dan PT. Pinus Merah Abadi dapat menambah sumber daya manusia. Pernyataan tersebut sejalan dengan penelitian yang dilakukan oleh Untari dkk. (2015), yang berjudul "Pengaruh Gaya Kepemimpinan Situasional terhadap Kinerja Aparatur Desa di Desa Tamansari Kecamatan Wuluhan Kabupaten Jember" adanya gaya kepemimpinan yang sesuai dengan situasi dan kondisi organisasi maka karyawan akan lebih bersemangat dalam menjalankan tugas dan kewajibannya dan mempunyai harapan terpenuhnya kebutuhan. 
TINJAUAN PUSTAKA

\section{Manajemen Sumber Daya Manusia}

Menurut (Kasmir 2019:6), manajemen sumber daya manusia adalah proses pengelolaan manusia, melalui perencanaan, rekrutmen, seleksi, pelatihan, pengembangan, pemberian kompensasi, karier, keselamatan dan kesehatan serta menjaga hubungan industrial sampai pemutusan hubungan kerja guna mencapai tujuan perusahaan dan peningkatan kesejahteraan stakehoder.

\section{Gaya Kepemimpinan}

Menurut Mintarsih dan Yuni Anisya (2019), Gaya Kepemimpinan adalah suatu cara pemimpin untuk mempengaruhi bawahannya, agar mau bekerja sama dan bekerja secara produktif untuk mencapain tujuan organisasi. Oleh karena itu gaya kepemimpinan dimaksudkan sebagai cara berperilaku yang khas dari seorang pemimpin terhadap para anggota kelompok. Dengan demikian, gaya kepemimpinan adalah cara pemimpin berperilaku secara konsisten terhadap bawahan sebagai anggota kelompok.

a. Gaya Kepemimpinan Transformasional

Menurut (Kharis 2015:3), Gaya kepemimpinan transformasional adalah tipe pemimpin yang menginspirasi para pengikutnya untuk mengenyampingkan kepentingan pribadi mereka dan memiliki kemampuan mempengaruhi yang luar biasa. Aspek utama dari kepemimpinan transformasional adalah penekanan pada pembangunan pengikut.

b. Gaya Kepemimpinan Demokratis

Menurut (Meutia, 2017), Gaya kepemimpinan demokratis/democratic adalah gaya kepemimpinan yang memberikan wewenang secara luas kepada para bawahan. Dalam gaya kepemimpinan democratis, pemimpin memberikan banyak informasi tentang tugas serta tanggung jawab bawahannya.

\section{Indikator Gaya Kepemimpinan}

Menurut (Susanti, 2015), indikator untuk mengukur gaya kepemimpinan demokratis adalah:

a) Kemampuan mendorong para bawahan untuk menggunakan daya kognitif dan daya nalarnya dalam pemecahan berbagai masalah yang dihadapi.

b) Mendorong penggunaan daya inovasi dan kreatifitas dalam pelaksanaan tugas.

c) Pemimpin dan bawahan sama-sama terlibat dalam pengambilan keputusan atau pemecahan masalah.

d) Hubungan antara pimpinan dan hawahan terjalin dengan baik.

Menurut (Robbins dan Judge, 2008; Widayati dkk., 2017), mengatakan terdapat empat indikator kepemimpinan transformasional, yaitu:

1. Pengaruh Ideal (Idealized Influence), adalah perilaku pemimpin yang memberikan visi dan misi, serta mendapatkan respek dan kepercayaan bawahan.

2. Motivasi Inspirasional (Inspirational Motivation), adalah perilaku pemimpin yang mampu mengkomunikasikan harapan yang tinggi, dan menginspirasi bawahan untuk mencapai tujuan yang menghasilkan kemajuan penting bagi organisasi.

3. Stimulasi Intelektual (Intellectual Stimulation), adalah perilaku pemimpin yang mampu meningkatkan kreativitas dan inovasi bawahan, meningkatkan rasionalitas, dan pemecahan masalah secara cermat. 
4. Pertimbangan Individual (Individualized Consideration), adalah perilaku pemimpin yang memperlakukan masing-masing bawahan sebagai seorang individu dengan kebutuhan, kemampuan, dan aspirasi yang berbeda, serta melatih dan memberikan saran.

\section{Kinerja Karyawan}

Menurut (Susanti, 2015), kinerja karyawan adalah gambaran hasil kerja yang berupa pencapaian pelaksanaan kegiatan yang didapat oleh karyawan baik secara mandiri maupun kelompok sesuai dengan aturan, wewenang serta sesuai dengan etika dan moral. Menurut (Susanti, 2015), indikator yang digunakan untuk mengukur kinerja karyawan adalah:

1. Kualitas pekerjaan: Tingkat sejauh mana proses atau hasil pelaksanaan kegiatan mendekatikesempurnaan atau mendekati tujuan yang diharapkan.

2. Kuantitas pekerjaan: Jumlah yang dihasilkan, misalnya jumlah rupiah, jumlah unit, jumlah siklus kegiatan yang diselesaikan.

3. Ketepatan waktu: Sejauh mana suatu kegiatan diselesaikan pada waktu yang dikehendaki dengan memperhatikan koordinasi output lain serta waktu yang tersedia untuk kegiatan yang lain.

\section{METODE PENELITIAN}

\section{Lokasi dan waktu penelitian}

Lokasi dari objek penelitian ini adalah PT. Pinus Merah Abadi. Perusahaan yang bergerak dibidang distributor makanan ringan yang beralamatkan di Jl. Sinar Pergudangan Gedangan Block B No. 08 Sidoarjo. Waktu penelitian berlangsung mulai Januari 2021 sampai Desember 2021. Dilakukan sampai dengan data yang diperlukan sudah lengkap sesuai dengan kebutuhan peneliti.

\section{Pendekatan Penelitian}

Pendekatan dilakukan dengan pendekatan deskriptif kualitatif. Berdasarkan sumbernya, jenis data yang digunakan dalam penelitian ini adalah data primer dan sekunder.

\section{Populasi dan Sampel}

Peneliti menggunakan seluruh karyawan sebagai responden. Teknik nonprobability sampling yang dipilih yaitu dengan sampling jenuh. Menurut (Sugiyono 2019:133) menyatakan bahawa "Sampling jenuh adalah teknik penentuan sampel bila semua anggota populasi digunakan sebagai sampel". Dengan kata lain sampling jenuh bisa disebut dengan sensus, dimana seluruh anggota populasi dijadikan sebagai sampel, hal ini sering dilakukan bila jumlah populasi relatif kecil, kurang dari 30 orang. Target responden dalam penelitian ini yaitu individu, baik laki-laki maupun perempuan yang menjadi karyawan PT. Pinus Merah Abadi cabang Sidoarjo.

\section{Metode Pungumpulan Data}

Dalam penelitian ini menggunakan metode pengumpulan data melalui wawancara, observasi, penyebaran kuesioner dan dokumentasi. 
Analisis Data

Menganalisis data dalam penelitian ini menggunakan Data Collection (Pengumpulan Data), Data Reduction (Reduksi data), dan Data Display (Penyajian Data).

\section{Teknik Keabsahan Data}

Teknik pemeriksaan keabsahan data yang digunakan dalam penelitian ini adalah teknik Triangulasi.Dalam penelitian ini peneliti menggunakan teknik pemeriksaan keabsahan data triangulasi sumber.

\section{HASIL ANALISIS DAN PEMBAHASAN}

Hubungan antara pimpinan dan para bawahan berkolerasi secara baik. Baik itu secara komunikasi maupun secara hubungan antar individu. Hal ini tentunya ada kaitannya dengan gaya kepemimpinan yang diterapkan oleh pemimpin dalam setiap perusahaan karena kemajuan perusahaan sangat dipengaruhi oleh kinerja karyawannya.Saat peneliti melakukan pengamatan dikantor PT. Pinus Merah Abadi pemimpin menjalankan perannya dengan baik sebagai kapasitasnya menjadi seorang pemimpin, dan bawahan juga berusaha menjalankan tugasnya dengan baik dan penuh tanggung jawab. Salah satu tugas yang harus dilakukan seorang sales merchandiser yaitu diwajibkan mencapai target untuk setiap bulannya dengan target yang telah ditentukan oleh perusahaan dan memastikan barang yang ada ditoko terdisplay dan tertata dengan rapi. Namun karena PT. Pinus Merah Abadi bergerak dibidang makanan ringan dan minuman tentunya berkaitan dengan expired sehingga semua karyawan harus memperhatikan soal expired barang.

Bu Yovita Soviana merupakan branch manager bagian modern trade (MT) PT. Pinus Merah Abadi cabang Sidoarjo. Untuk mencapai tujuan perusahaan Bu Yovita menerapkan beberapa hal dalam upaya meningkatkan kinerja karyawannya hal tersebut dilakukan agar kegiatan pada perusahaan bisa terarah secara jelas dan sesuai dengan tujuan perusahaan. Selain itu, Bu Yovita selalu menghargai para bawahannya dalam pengambilan keputusan dan pelaksanaan tugas yang telah ditentukan oleh perusahaan. hal tersebut membuat para kayawan merasakan kepercayaan, kekaguman, kesetiaan, dan penghormatan terhadap pimpinannya, serta membuat para karyawan sales merchandiser merasa termotivasi untuk melakukan pekerjaan yang lebih baik lagi.

Gaya kepemimpinan yang digunakan oleh Bu Yovita dapat membuat rencana perubahan besar dan terarah terhadap visi, misi, dan strategi PT. Pinus Merah Abadi cabang Sidoarjo dengan mengambil keputusan sesuai dengan tujuan organisasi dan mengutamakan musyawarah untuk kepentingan bersama. Meskipun terkadang memiliki pendapat yang berbeda terhadap karyawan, Bu Yovita menghargai setiap perbedaan pendapat untuk tujuan kearah yang lebih baik, dan memberikan contoh yang baik bagi seluruh karyawannya untuk menghormati perbedaan.

Dari teori yang telah dipelajari dalam Bab II bahwa pemimpin PT. Pinus Merah Abadi cabang Sidoarjo menggunakan Gaya Kepemimpinan Transformasional yang telah dipelajari pada Bab II Menurut (Kharis 2015:3), Gaya Kepemimpinan Transformasional adalah tipe pemimpin yang menginspirasi para pengikutnya untuk mengenyampingkan kepentingan pribadi mereka dan memiliki kemampuan mempengaruhi yang luar biasa. Gaya kepemimpinan transformasional diterapkan oleh pemimpin pada saat pemimpin mempengaruhi dan membantu para anggota untuk tujuan-tujuan positif, menjaga 
kekompakan tim, menghargai perbedaan dan keyakinan, memiliki kepedulian terhadap para karyawan. Perilaku Bu Yovita yang memotivasi karyawan bagian sales modern trade dalam menginspirasi untuk mencapai tujuan yang dihasilkan dalam menyelesaikan tugas, sehingga perilaku tersebut merupakan salah satu indikator dari gaya kepemimpinan transformasional yang sudah ada di Bab II menurut (Robbins and Judge, 2008; Widayati dkk., 2017), Selain menggunakan gaya kepemimpinan transformasional pemimpin juga menggunakan gaya kepemimpinan demokratis. Gaya kepemimpinan demokratis/democratic menurut (Meutia, 2017), adalah gaya kepemimpinan yang mem-berikan wewenang secara luas kepada para bawahan. Dalam gaya kepemimpinan demokratis, pemimpin memberikan banyak informasi tentang tugas serta tanggung jawab bawahannya. Dalam teori gaya kepemimpinan demokratis diterapkan oleh pemimpin pada saat mengambil keputusan dan mengutamakan musyawarah untuk kepentingan bersama sesuai dengan tujuan perusahaan. Perilaku tersebut merupakan salah satu indikator gaya kepemimpinan demokratis menurut (Susanti, 2015), dimana pemimpin dan bawahan sama-sama ikut terlibat dalam pengambilan keputusan untuk penyelesaian masalah.

Teori gaya kepemimpinan demokratis dan gaya kepemimpinan transformasional ternyata diaplikasikan oleh pemimpin PT. Pinus Merah Abadi cabang Sidoarjo, walau pemimpin memiliki kepedulian, menghargai pendapat dan keyakinan setiap perbedaan pendapat. Kemudian pemimpin demokratis mengembangkan kreatifitas karyawan, mengutamakan musyawarah dengan kepentingan bersama sesuai tujuan organisasi, dan memandang semua masalah dapat dipecahkan dengan usaha bersama. Namun tidak semua yang dilakukannya bersifat demokratis. Hal ini juga menyatakan bahwa pemimpin PT. Pinus Merah Abadi cabang Sidoarjo tidak hanya menggunakan satu gaya transformasional saja tetapi juga menggunakan gaya kepemimpinan demokratis.

Gaya kepemimpinan transformasional terlihat dari cara pemimpin dalam hal pendekatan baik kepada para semua karyawan dan memiliki kepedulian terhadap lingkungan dan kenyamanan kerja, dan merangsang tujuan-tujuan positif menjaga kekompakan tim, dan menghargai perbedaan dan keyakinan. Sedangkan mengenai gaya kepemimpinan demokratis terlihat dari dalam cara pimpinan mengutamakan musyawarah dan kepentingan bersama dalam mencapai tujuan perusahaan.

Tabel 1

Uji Keabsahan Triangulasi Sumber

\begin{tabular}{lll}
\hline No. & Indikator & Gaya Kepemimpinan \\
\hline 1. & Kemampuan mendorong para bawahan & \\
2. & $\begin{array}{l}\text { Mendorong penggunaan daya inovasi dan kreatifitas dalam } \\
\text { pelaksanaan tugas. }\end{array}$ & \multicolumn{1}{c}{ Kepemimpinan } \\
3. & $\begin{array}{l}\text { Pemimpin dan bawahan sama-sama terlibat dalam } \\
\text { pengambilan keputusan atau pemecahan masalah. } \\
\text { Demokratis }\end{array}$ \\
4. & $\begin{array}{l}\text { Hubungan antara pimpinan dan hawahan terjalin dengan } \\
\text { baik. }\end{array}$ & \\
5. & Pengaruh Ideal & Gaya Kepemimpinan \\
6. & Motivasi Inspirasional & Transformasional \\
7. & Stimulasi Intelektual & \\
8. & Pertimbangan Individual & \\
\hline
\end{tabular}

Sumber: Peneliti (2021) 
Menurut hasil wawancara pada pemimpin PT. Pinus Merah Abadi cabang Sidoarjo dan keempat narasumber lainnya adalah karyawan pada perusahaan tersebut, maka peneliti menganalisis gaya kepemimpinan yang diterapkan oleh pada pemimpin PT. Pinus Merah Abadi cabang Sidoarjo yang dapat dibedakan berdasarkan indikator yang terdapat pada Tabel 1.

\section{Gaya Kepemimpinan Demokratis}

1. Kemampuan mendorong para bawahan

Wawancara yang dilakukan dengan karyawan mengatakan: "pencapaian target karyawan sales ada nilai nominalnya jadi sayang sekali kalau ada promo menarik namun terlewatkan sehingga saya selalu melakukan evaluasi"

2. Mendorong penggunaan daya inovasi dan kreatifitas dalam pelaksanaan tugas.Pemimpin PT. Pinus Merah Abadi cabang Sidoarjo selalu mengingatkan para karyawan agar terus berinovasi dan melakukan kreatifitas masing-masing, hal tersebut dilakukan agar karyawan dapat berkembang.

3. Pemimpin dan bawahan sama-sama terlibat dalam pengambilan keputusan atau pemecahan masalah.

Setiap melakukan meeting pemimpin selalu memberikan kesempatan bagi karyawan untuk menyampaikan pendapatnya dalam mengambil keputusan.Cara pengambilan keputusan yang dilakukan oleh pemimpin PT. Pinus Merah Abadi cabang Sidoarjo lebih cenderung sesuai dengan gaya kepemimpinan demokratis yaitu melibatkan karyawan dalam pengambilan keputusan memotivasi karyawan agar tidak hanya sebagai "pelaku" keputusan tapi juga membangun kemampuan karyawan agar dapat bertumbuh sebagai seorang pribadi yang lebih hebat di dalam pengambilan keputusan.

4. Hubungan antara pimpinan dan hawahan terjalin dengan baik.

Sedangkan mengenai hubungan antara pimpinan dan hawahan terjalin dengan baik oleh Pemimpin PT. Pinus Merah Abadi cabang Sidoarjo adalah dengan membangun interaksi tidak hanya di dalam jam kerja tetapi juga di luar jam kerja melalui adanya beberapa acara setiap tahunnya dan pada saat-saat tertentu mengajak beberapa karyawan makan bersama dan saling bercerita satu sama lain. Di dalam hal membangun hubungan dan interaksi antara pemimpin dan karyawannya Pemimpin PT. Pinus Merah Abadi cabang Sidoarjo lebih cenderung menggunakan gaya kepemimpinan Demokratis dikarenakan setiap interaksi dan hubungan yang dibangun bukan semata karena terikat dengan pekerjaan dalam perusahaan yang sama tetapi melainkan inisiatif dari pada direktur sendiri untuk membangun hubungannya dengan mengusulkan mengadakan perencanaan kegiatan tertentu setiap tahunnya kemudian mengajak beberapa karyawannya makan bersama pada saat-saat tertentu bahkan memberikan kejutan kepada karyawan yang berulang tahun.

\section{Gaya Kepemimpinan Transformasional}

1. Pengaruh Ideal

PT. Pinus Merah Abadi cabang Sidoarjo memberikan keterbukaan terhadap informasi hampir kepada seluruh karyawan seperti perkembangan perusahaan, kondisi perusahaan, hasil penjualan dan lain lain. Informasi tersebut terbuka hingga 
kepada seluruh struktur dalam perusahaan. Keterbukaan informasi tersebut cenderung menggunakan gaya kepemimpinan transformasional dengan adanya keterbukaan informasi kepada seluruh struktur di perusahaan tersebut maka akan memotivasi karyawan untuk melakukan lebih dari pekerjaan yang dilakukan demi keberlangsungan dan kesuksesan perusahaan bersama sehingga perusahaan yang sejahtera akan dapat menyejahterakan karyawannya.

2. Motivasi Inspirasional

Pemimpin PT. Pinus Merah Abadi cabang Sidoarjo selalu memberikan motivasi kepada karyawan agar bisa bekerja sama, selalu lebih baik dari sebelumnya dan capai target sesuai jobdesknya.

3. Stimulasi Intelektual

Perilaku pemimpin yang mampu meningkatkan kreativitas dan inovasi bawahan, meningkatkan rasionalitas, dan pemecahan masalah secara cermat. Hal ini ditunjukkan oleh pemimpin PT. Pinus Merah Abadi cabang Sidoarjo dengan cara mengajukan beberapa promo agar karyawan sales merchandiser dapat capai target.

4. Pertimbangan Individual

Dalam pertimbangan individual tentunya pemimpin memiliki penilaian masingmasing kepada bawahannya, salah satu penilaian tersebut dapat dilihat dan dinilai langsung dari cara karyawan sales dalam melaksanakan tugasnya dan dilihat dari data incentive yang diperoleh karyawan.

Gaya kepemimpinan yang diterapkan oleh pemimpin PT. Pinus Merah Abadi cabang Sidoarjo diharapkan dapat membangun pola pikir serta kinerja yang baik dan maju. Sehingga berdampak pada peningkatan kinerja karyawan bagian sales modern trade PT. Pinus Merah Abadi cabang Sidoarjo karena pemimpin merupakan roda penggerak dan perubahan bagi bawahannya.

Melalui gaya kepemimpinan transformasional dan demokratis yang diterapkan oleh pemimpin diharapkan mampu mewujudkan perusahaan distribusi yang tumbuh dengan berfokus pada pengembangan sumber daya manusia, sistem distribusi, inventaris, dan praktek perusahaan yang baik.

Dari gaya kepemimpinan yang diterapkan terlihat jelas bahwa pemimpin PT. Pinus Merah Abadi cabang Sidoarjo telah mengaplikasikan diantara kedua hal tersebut, baik itu reward dan motivasi berupa dukungan moril oleh pemimpin secara langsung. Setelah penerapan teori yang ada, dengan semakin disiplinnya para karyawan dan dedikasi yang tinggi terhadap lembaga dan juga pemahaman program secara komprehensif. Hal tersebut membuktikan secara tidak langsung bahwa kinerja para karyawan sales modern trade PT. Pinus Merah Abadi cabang Sidoarjo terpengaruhi oleh gaya kepemimpinan yang diterapkan.

\section{SIMPULAN DAN SARAN}

Dari hasil penelitian ini Pemimpin PT. Pinus Merah Abadi cabang Sidoarjo telah menjalankan fungsinya sebagai kepemimpinan secara baik. Mengenai gaya kepemimpinan yang diterapkan oleh pemimpin PT. Pinus Merah Abadi cabang Sidoarjo lebih cenderung menggunakan gaya kepemimpinan transformasional. Gaya kepemimpinan transformasional tersebut terlihat dari bagaimana cara pemimpin memiliki rencana perubahan besar dan terarah terhadap visi, misi dan strategi perusahaan 
dan saat pemimpin memberi perintah terhadap para karyawan tanpa ada tekanan. Namun Pemimpin PT. Pinus Merah Abadi juga menggunakan gaya kepemimpinan demokratis. Gaya kepemimpinan tersebut terlihat dari pemimpin mengutamakan musyawarah dan mengambil keputusan sesuai dengan tujuan perusahaan.

\section{DAFTAR PUSTAKA}

Achmad Daengs, G. S., Istanti, E., Bramastyo Kusuma Negoro, R. M., \& Sanusi, R. (2020). The Aftermath of Management Actions on Competitive Advantage Through Process Attributes at Food and Beverage Industries Export Import in Perak Harbor of Surabaya. International Journal of Criminology and Sociology, 9, 14181425. https:/ / doi.org/10.6000/1929-4409.2020.09.162.

Achmad Daengs GS1, Enny Istanti, M. Y. R. P. (2021). Challenges of Exchange Rate Fluctuation and Cpo Prices in Indonesia Palm Oil Industry. IJEBD, 04 (03), 356362. https://doi.org/https://doi.org/10.29138/ijebd.v4i3.1379.

Daengs GS, A., Kurniasih, N., Reni, A., Istanti, E., Zuhroh, D., \& Qomariah, N. (2019). The Effect of Business Sphere on Competitive Advantage and Business Performance of SMEs. Management Science Letters, 9 (8), 1153-1160. https://doi.org/10.5267/j.msl.2019.4.025.

Enny Istanti1), Bramastyo Kusumo2), I. N. (2020). Implementasi Harga, Kualitas Pelayanan dan Pembelian Berulang pada Penjualan Produk Gamis Afifathin. Ekonomika'45, 8(1), 1-7. https://univ45sby.ac.id/ejournal/index.php/akuntansi45/article/view/64/50.

Enny Istanti1, Bramastyo Kusumo Negoro2, A. D. G. (2021). The Effect of Work Stress and Financial Compensation, Ocb on Employee Performance (Case Study at PT. Mentari Sejati Perkasa Private Company in Surabaya). Media Mahardhika, 19(3), 560-569. https://doi.org/10.29062/mahardika.v19i3.280.

Enny Istanti, Amaliyah, Achmad Daengs, G. (2020). Work Productivity Through Compensation, Experiences, and Walfare Benefits PT Summit Otto Finance Surabaya. SINERGI, 10(2), 27-36.

Enny Istantia, AchmadDaengsGSb, FadjarBudiantoc, Indah Noviandarid, R. S. (2020). The Influences of Motivation, Work Milieu, and Organizational Commitment on Teacher Performance in MTS Negeri 4 ( Public Islamic School), Surabaya East Java. International Journal of Innovation, Creativity and Change, 13(2), 629-642. www.ijicc.net. 
Ennyistanti, Ruchansanusi, A. D. G. (2020). Impacts of Price, Promotion and Go Food Consumer Satisfaction in Faculty of Economic and Business Students of Bhayangkara University Surabaya. Ekspektra:Jurnal Bisnis dan Manajemen, 4(2), 104120. https://doi.org/10.25139/ekt.v4i2.3134.

Enny Istanti, Bramastyo Kusumo, I. N. (2020). Implementasi Harga, Kualitas Pelayanan dan Pembelian Berulang pada Penjualan Produk Gamis Afifathin. Ekonomika 45, 8(1), 1-10.

Enny Istanti. (2020). Pegawai Menggunakan Metode Analysis Gap di Kantor Kecamatan Simokerto Surabaya, Jurnal Ilmiah Edunomika, 04(02), 378-385.

Istanti, E., Kn, R. M. B., \& Gs, A. D. (2021). Efforts to Empower MSMEs in Panci Village in Increasing Family Income (Study on MSMEs in Panci Village in Porong District, Sidoarja Regency ). $2021(2), 497-504$.

Istanti, E. (2019). Pengaruh Harga, Promosi Dan ProdukTerhadap Keputusan Pembelian Di Restoran Burger King Kawasan Surabaya Plaza Surabaya. Ekonomika 45, 7(1), 16-22. https://doi.org/.1037//0033-2909.I26.1.78.

Istanti, E. (2016). Pengaruh Kecerdasan Emosional terhadap Prestasi Belajar Mahasiswa Fakultas Ekonomi Manajemen Universitas Bhayangkara Surabaya. Ekonomika'45, 3(02), 119. http://jurnal.univ45sby.ac.id/index.php/ekonomi/article/view/119.

Istanti, E., Negoro, B. K., \& GS, A. D. (2021). Analysis of Factors Affecting Income Distribution Inequality in Indonesia 2009-2013 Period. International Journal of Entrepreneurship and Business Development, 4(02), 157-163.

Meutia, T. (2017). Pengaruh Budaya Organisasi, Gaya Kepemimpinan dan Motivasi Kerja terhadap Kinerja Karyawan pada PT. PLN (persero) Wilayah I Aceh. Jurnal Penelitian Ekonomi Akuntansi (JENSI), 1(2), 113-123.

Mintarsih dan Yuni Anisya. (2019). Pengaruh Gaya Kepemimpinan terhadap Kinerja Karyawan Bagian Pengadaan Barang pada PT. Indomarco Prismatama (Indomaret Group). Jurnal Manajemen Bisnis, 05(01), 1-11.

Sugiyono, P. D. (2018). Metode Penelitian Kuantitatif, Kualitatif, dan RひD. ALFABETA.

Widayati, C., H. Rahardjo, T., \& Febriyanti, M. (2017). Pengaruh Gaya Kepemimpinan Transformasional, Motivasi Dan Kompensasi Terhadap Kinerja Karyawan. Jurnal Ekonomi, 22(3), 466-485. https://doi.org/10.24912/je.v22i3.286. 